\title{
Assessment of Haemostasis in Anaesthesia for Surgery at the Sylvanus Olympio University Hospital Center in Lomé
}

\author{
Essohanam T. Mouzou 1,2*, Sarakawabalo Assénouwè1, Abd El Kader Moumouni³, \\ Pikabalo Tchètikè2, Akala-Yoma Gnimdou²
}

${ }^{1}$ Anesthesilogy Department, University Teaching Hospital of Kara, Kara, Togo

${ }^{2}$ Anesthesiology Department, Sylvanus Olympio Teaching Hospital, Lome, Togo

${ }^{3}$ Neurosurgery Department, University Teaching Hospital of Kara, Kara, Togo

Email: *essohanam2004@yahoo.fr.

How to cite this paper: Mouzou, E.T., Assénouwè, S., Moumouni, A.E.K., Tchètikè, P. and Gnimdou, A.-Y. (2021) Assessment of Haemostasis in Anaesthesia for Surgery at the Sylvanus Olympio University Hospital Center in Lomé. Open Journal of Anesthesiology, 11, 184-193. https://doi.org/10.4236/ojanes.2021.116018

Received: April 10, 2021

Accepted: June 18, 2021

Published: June 21, 2021

Copyright $\odot 2021$ by author(s) and Scientific Research Publishing Inc. This work is licensed under the Creative Commons Attribution International License (CC BY 4.0).

http://creativecommons.org/licenses/by/4.0/

\section{(c) (i) Open Access}

\begin{abstract}
Title: Assessment of haemostasis in anaesthesia for surgery at the Sylvanus Olympio University Hospital Center in Lomé. Objectives: Evaluate the prescription of the preoperative haemostasis assessment. Methodology: This was a prospective descriptive and observational study which had taken place in the central operating room and in the operating room of the ENT department at UHC SO of Lomé from January 1 to June 31, 2016. It had concerned all patients who had anaesthesia for scheduled surgery after pre-anesthetic consultation and the haemostasis assessment carried out according to the anaesthesia technique and the type of surgery. Results: Two hundred and sixty (260) patients underwent anaesthesia during the study period. The male sex predominated (60\%), the age group 18 - 40 years predominated (50.4\%). GA was more practiced $(62.7 \%)$ followed by spinal anaesthesia (30.3\%). Minor ENT surgery was more performed (28\%). ASA1 patients predominated (48.5\%). The pre-anesthetic haemostasis assessment including platelet count, prothrombin rate, activated partial thromboplastin time and bleeding time was almost always done. The platelet count was achieved in all patients followed by the activated partial thromboplastin time (94\%). No haemorrhagic complication related to a haemostasis disorder was observed in the perioperative period in anaesthesia than in surgery. Conclusion: The prescription of the pre-anesthetic haemostasis assessment should not be systematic. It must take into account the clinical history, the patient's bleeding history during the anaesthesia consultation, the type of anaesthesia, the surgery planned and the age.
\end{abstract}




\section{Keywords}

Haemostasis Assessment, Anaesthesia, Surgery, UHC, Lomé

\section{Introduction}

Before the practice of anaesthesia of general (GA) or locoregional (LRA), several clinical and paraclinical examinations are carried out. Thus a routine preoperative haemostasis assessment (PHA) to detect any haemostasis abnormalities is likely to increase the risk of bleeding [1].

In Europe, particularly in France, PHA to screen for a haemostasis disorder before anaesthesia is no longer systematic [2] [3].

In French-speaking black Africa, the selective prescription of a PHA remains topical [4].

No study was done in Togo on PHA to determine a selective prescription strategy. The aim was to assess the prescription of PHA in anaesthesia at the UHC-Sylvanus Olympio (SO).

\section{Methodology}

Our study was carried out in the central operating rooms and in otorhinolaryngology (ENT) and maxillofacial surgery (MFS) of the UHC SO in Lomé.

This prospective descriptive and observational study was carried out over a period of 6 months from January 1 to June 31, 2016. It began after authorization from the UHC SO ethics and patient protection committee and informed consent of patients to the consultation of anesthesia.

It concerned all patients who had anaesthesia for scheduled surgery after a preanaesthetic consultation. All patients operated without a preanaesthetic consultation with anaesthesia-resuscitation doctor (ARD) were excluded from the study. Anaesthesia consultation records, anaesthesia monitoring records for postoperative and anaesthesia were the means used for data collection. The parameters studied were: socio-demographic parameters; haemorrhagic history; haemorrhagic clinical aspects; anaesthetic and surgical aspects; biological abnormalities of PHA; abnormal per and postoperative bleeding; the conduct in front of haemostasis anomalies.

A count was manual. The processing was carried out by the Word 2007 computer software.

\section{Results}

\subsection{Epidemiological Aspects}

During the study period, 270 patients were operated on for scheduled surgery, of which 260 were included in the study, a frequency of $0.96 .57 .7 \%$ of the patients were operated on in the central block and $42.3 \%$ in the ENT block. 
The age of the patients is presented in Table 1.

The average age of our patients was 40 years with extremes of 8 months and 87 years. $60 \%$ of patients were male.

No preoperative patient had clinical signs of a haemostasis disorder or a history of bleeding related to a haemostasis disorder.

The PHA performed was composed: bleeding time (BT) $72.7 \%$; activated partial thromboplastin time (APTT) 95\%; prothrombin rate (PR) 95.4\%; platelet count $(100 \%)$ with $7.7 \%$ high platelet rate and $0.4 \%$ low platelet rate; $11.3 \%$ low PR; $6.5 \%$ of elongated APTT and $5.8 \%$ of elongated BT.

The preoperative treatments for haemostasis abnormalities were as follows: 11.3\% PR of which $6.4 \%$ had received vitamin $\mathrm{K} 1+0.8 \%$ a transfusion of fresh frozen plasma. $0.4 \%$ of severe thrombocytopenia had received platelet concentrate and had undergone a specialist haematology consultation or no haemostasis abnormality had been found. For patients with BT, prolonged APTT and high platelet count, no treatment was performed.

The PHA according to the age of the patients was as follows:

8 months to 3 years (14.6\%): BT (10.3\%), PR (13.4\%); APTT (14.6\%); platelets (14.6\%); from 4 to 55 years old (64.6\%): BT (47.3\%); PR (58.4\%); APTT (56.9\%); platelets (64.6\%);

56 to 87 years old (20.8\%): BT (15\%); PR (19\%); APTT (20\%); platelets (20.7\%).

ASA classification is presented in Table 2.

PHA performed according to ASAl: platelets (48.5\%); APTT (44.6\%); PR (43\%); BT (35.4\%); for ASA2: platelets (40\%); APTT (38\%); PR (37.6\%); BT (34.6\%); for ASA3: platelets (11.5\%); APTT (11.1\%): PR (11.1\%); BT (6.5\%).

Table 1. Distribution of patients by age.

\begin{tabular}{ccc}
\hline Year & Effective & Percentage \\
\hline$[0-18]$ & 46 & 17.7 \\
{$[18-41]$} & 131 & 50.4 \\
{$[41-61]$} & 62 & 23.8 \\
{$[61-87]$} & 21 & 8.1 \\
TOTAL & 260 & 100 \\
\hline
\end{tabular}

Table 2. Distribution of patients according to class ASA*.

\begin{tabular}{rcc}
\hline & Effective & Percentage \\
\hline ASA1 & 126 & 48.5 \\
ASA2 & 104 & 40 \\
ASA3 & 30 & 11.5 \\
TOTAL & 260 & 100 \\
\hline
\end{tabular}

${ }^{*}$ American society of anaesthesiologists. 


\subsection{Intraoperative Stage}

Types of anaesthesia are presented in Table 3.

During the intraoperative period, no incident occurred during anaesthesia related to haemostasis disorder. The same observation was made postoperatively.

Surgical aspects are presented in Table 4.

Major surgery is presented in Table 5.

Minor surgery is presented in Table 6.

Table 3. Distribution of patients according to the type of anaesthesia.

\begin{tabular}{ccc}
\hline & Effective & Percentage \\
\hline GA & 163 & 62.7 \\
Spinal anesthesia & 79 & 30.3 \\
Axillary block & 8 & 3.1 \\
Caudal block & 7 & 2.7 \\
Epidural & 3 & 1.2 \\
TOTAL & 260 & 100 \\
\hline
\end{tabular}

Table 4. Distribution of patients by type of surgery.

\begin{tabular}{lcc}
\hline & Effective & Percentage \\
\hline (1) Minor ENT surgery & 73 & 28 \\
(2) Minor abdominal surgery & 54 & 20.8 \\
(3) Major orthopedic surgery & 34 & 13 \\
(4) Major abdominal surgery & 30 & 11.5 \\
(5) Major ENT surgery & 29 & 11 \\
(6) Minor orthopedic surgery & 24 & 9.2 \\
(7) Other major surgeries & 11 & 4.2 \\
(8) Other minor surgeries & 5 & 1.9 \\
TOTAL & 260 & 100 \\
\hline
\end{tabular}

(1) adenoidectomy, tonsillectomy, adeno-tonsillectomy. (2) Hernial cure, hydrocele cure, fistulectomy. (3) Osteosynthesis of the femur, hip. (4) Gastrectomy, abdominal lumpectomy. (5) Laryngectomy, thyroidectomy, ENT sphere lumpectomy. (6) Removal of osteosynthesis materials, external fixators, osteosynthesis of the legs and upper limbs. (7) Neurosurgery. (8) Skin graft, varicectomy, arterovenous fistula.

Table 5. Haemostasis assessment following major surgery.

\begin{tabular}{ccc}
\hline & Effective & Percentage \\
\hline Platelets & 104 & 40 \\
APTT & 96 & 37 \\
PR & 93 & 35.7 \\
BT & 68 & 26 \\
\hline
\end{tabular}

Table 6. Haemostasis balance according to minor surgery.

\begin{tabular}{ccc}
\hline & Effectif & Pourcentage \\
\hline Platelets & 156 & 60 \\
APTT & 151 & 58 \\
PR & 146 & 56 \\
BT & 121 & 46.5 \\
\hline
\end{tabular}




\section{Discussion}

\subsection{Epidemiological Aspects}

Two hundred and sixty patients were involved in the study: $57.7 \%$ in the central block and $42.3 \%$ in the ENT block. The number of patients was reduced due to the reduction of surgical operations at the central block during the development work during the study period. The 18 to 40 age group was the most represented with $50.4 \%$. The average age of the patients was 40 years. Our results are close to that of Sorol [6] with 59\% for the same age group. Anaesthesia was more practiced in young adults at UHC-SO. The male sex predominated (60\%). This result can be superimposed on those of Sorol and Béyé [5] [6] with $63 \%$ and $57.4 \%$ respectively.

\subsection{Anaesthesiological Care}

All of the patients had undergone anaesthesia consultation prior to the practice of anaesthesia.

The PHA was systematic. The platelet count was achieved in all patients. This result is identical to that of Koumare [7] with $99.6 \%$ platelet count achieved preoperatively. The prothrombin (PR) level was performed at $95.3 \%$ with an abnormal PR of $11.7 \%$. This abnormal PR was slightly higher than that of Koumare [7] with $7.14 \%$. APTT was $95 \%$ performed with $6.5 \%$ abnormal APTT. The BT was $72.7 \%$ achieved with $5.8 \%$ abnormal BT. These abnormal results in our context are partly false positives by laboratory errors. Blery [8] recommends in this case the abandonment of a systematic prescription and favour a selective prescription.

Several authors Samama CM [2], Haberer [9] have questioned the importance of BT in PHA. For Dominique [10], the preoperative BT does not have a good predictive value for the risk of haemorrhage per and postoperatively, whatever the type of anaesthesia in the absence of haemorrhagic manifestation of primary haemostasis. The only discordant argument is that of the Study Group on Haemostasis and Thrombosis (SGHT) [11] of the French society of haematology, which defends a minimal PHA including a level of platelets, a PR, a APTT in all preoperative patients. In our context, the prescription of PHA did not take account of the interrogation or clinical examination but was systematically prescribed most often by the surgeons who received the patients first and the paramedical anaesthesiologists who did not have the same skills than the ARD in this area. The prescription of PHA should not be systematic and the bleeding time should not be part of PHA [10] [12] [13].

The preoperative treatment of the haemostasis anomalies observed was carried out for $6.4 \%$ of low PR with vitamin $\mathrm{K} 1$ and $0.8 \%$ with fresh frozen plasma. A patient with severe thrombocytopenia was transfused with platelet concentrate and had no haemostasis pathology after haematological consultation. For Tetchi [14], the frequency of pathologies revealed by a systematic PHA in patients in whom the examination and clinical examination are normal is low. No treat- 
ment was performed for the other haemostasis abnormalities found. The various abnormalities of haemostasis come from other pathologies interfering with haemostasis, false positives, taking certain drugs interfering with haemostasis, non-compliance with the conditions of sampling for good haemostasis and not pathologies of haemostasis.

The children 8 months to 3 years old had all benefited from a sample for a platelet count and a APTT at 14.6\%; 13.4\% PR and 10.3\% BT. Our results are different from those of Molliex [12] and the recommendations of the National Agency for Accreditation and Health Assessment (NAAHA) [15], which recommend carrying out PR, APTT and platelet count to diagnose a haemorrhagic syndrome preoperatively even in the absence of a haemorrhagic history before walking age in children. The patients aged 45 to 55 all had a platelet count (64.6\%); 58.4\% PR; 56.9\% APTT and 47.3\% BT. According to Molliex and NAAHA [12] [15], PHA is not necessary in this age group if the examination for haemorrhagic syndrome is negative. Our results in this age group contradict this argument and did not take age into account. For those over 55, the NAAHA [15] recommends the prescription of PR, APTT and platelet count even if the examination is negative. The NAAHA recommendations [15] differ from our results in this age group where all the patients had a platelet count (20.7\%); PR (20\%), APTT (19\%) and BT (15\%). These results in our context were related to the fact that the majority of PHAs were not requested by the MARs at the consultation but rather by the surgeons and by the paramedical anaesthetists.

ASA1 patients were more represented (48.5\%) followed by ASA2 (40\%) and ASA3 patients (11.5\%). Our results are close to those of Tomta [16] who found $53.2 \%$ of ASA1. On the other hand, these results are lower than those of Sorol [5] with 60\% of ASA1. Indeed Molliex, Bonhomme and Haberer [12] [13] [17] had questioned the systematic nature of this prescription for ASA1 patients. Asymptomatic haemostasis disorders are exceptional in ASA1 subjects and the systematic practise of PHA in the ASA1 population generates very many false positive results according to Blery and Haberer [1] [17] so it is necessary to take into account the history in favour of a haemostasis disorder. In ASA2 and ASA3 patients, PHA was performed systematically. The ASA classification did not directly influence the achievement of PHA.

\subsection{Intraoperative Stage}

General anaethesia (GA) was the most common technique (62.7\%). This result can be explained by the fact that all ENT and neurosurgery patients were operated on GA where other techniques were not possible.

According to anaesthesia techniques, the platelet count was achieved in all patients (Table 3). These results are contrary to the recommendations of David, ASA and NICE [18] [19] [20], according to which only the clinical examination and the interrogation should be carried out in first intention to diagnose a pathology of the coagulation before the practise of a anaesthesia whether general or 
locoregional. This systematic practise of PHA in our context was the work of the same previous actors (surgeons, paramedical anaesthesiologists). These systematic reviews were carried out in the haunt of optimal security for the prevention of haemorrhagic complications related to spinal anaesthesia.

No peranaesthetic incident related to a haemostasis disorder was recorded during our work; therefore, peranaesthetic incidents related to a haemostasis disorder were rare and a systematic PHA had been of no use.

No post-anaesthetic complications related to a haemostasis disorder were recorded. The occurrence of a post-anaesthetic complication linked to a haemostasis disorder, in particular compression marrow haematoma in the case of locoregional anaesthesia (LRA), was evaluated in a variable manner according to Nathan [21]. The haemorrhagic risk in case of peripheral LRA is considered to be less than that of central LRA due to the superficial nature of the puncture which makes compression available externally and the occurrence of even a small haematoma is directly visible.

The results of Nathan [21], can be superimposed on ours or no postoperative complication linked to a haemostasis disorder was recorded. For Nathan [21], the occurrence of a perimedullary haematoma is often linked to other favorable factors such as technical difficulties and the repetition of punctures, age but rarely to a haemostasis disorder. Although rare, post-anaesthetic complications related to a haemostasis disorder are a reality and should be taken into account whenever an anaesthesia, especially locoregional, is indicated.

Types of surgery: minor ENT surgery was the most represented (28\%) followed by minor abdominal surgery (20.7\%).

PHA performed for minor surgery: all patients who had minor surgery $(60 \%)$ performed a minimal haemostasis assessment including a platelet count (60\%), a APTT (58\%), a PR (56\%), a BT (46\%). These results are contrary to Tetchi's arguments [14] according to which if the patient has no haemorrhagic history subject to reliable questioning, if there is no pathology which could interfere with haemostasis and the estimated haemorrhagic risk of the operating procedure is low or even zero, so this PHA is unnecessary. The same arguments are shared by Samama [2] and Haberer [17]. On the other hand, the GEHT [11] recommends performing a simple PHA comprising a platelet count, a PR and a APTT in all preoperative patients. PHA is not necessary in case of minor surgery in the absence of elements in favour of a haemostasis disorder [12] [13] [19] [20].

PHA performed for major surgery: almost all patients operated for major surgery (40\%) had a platelet count (40\%), a APTT (37\%), a PR (35.7\%) and a BT (26\%).

Our results respond to the arguments of several authors [2] [12] [13] [19] who recommend the prescription of the level of platelets, APTT, and PR in the event of major surgery in all patients even in the absence of clinical sign and history in favour of a hemostasis disorder.

Intraoperative incidents and accidents: no intraoperative complications re- 
lated to a haemostasis disorder were recorded after the correction of biological haemostasis disorders. According to Blery [22], bleeding problems are much more linked to surgical problems than to a biological disorder of haemostasis. It is very unlikely to have a severe bleeding intraoperatively related to an unknown haemostasis abnormality in asymptomatic subjects. On the other hand, the occurrence of bleeding during surgery depends not only on the abnormality of physiological haemostasis but also on the type of surgery, the quality of surgical haemostasis and the taking of certain drugs that interfere with haemostasis. Numerous studies have shown that there is no close relationship between the abnormality of haemostasis and surgical bleeding [23].

Postoperatively there was no abnormal postoperative bleeding from operative wounds.

\section{Conclusion}

The risk of bleeding and peri-anesthetic complications due to an abnormality of haemostasis is an individual and not a statistical risk. The simple haemostasis assessment was systematic. No complications related to a haemostasis disorder were recorded during the perioperative period. The systematic prescription of the preoperative haemostasis assessment was hardly justified. Selectively prescribe the haemostasis balance according to the patient's age, clinical condition, field, surgical condition. For minor surgery, refrain from the haemostasis check-up; in case of major surgery, ask for a platelet count, a PR and an APTT.

\section{Acknowledgements}

Thanks to Isabelle Mouzou for the secretariat and Afi Hégbor for the English translation. The work is done in a more or less solitary setting.

\section{Conflicts of Interest}

The authors declare that they have no conflict of interest.

\section{Declaration}

The manuscript has been read and approved by all the authors and the conditions of authorship have been fulfilled.

\section{References}

[1] Blery, C. (1990) Should a Coagulation Assessment be Carried out before Locoregional Anesthesia in an ASA1 Subject? French Annale of Anesthesia and Resuscitation, 9, 371-374.

[2] Samama, C.M. (1996) Practical Conduct in Hemostasis in Manual of Hemostasis. Paris: LFP, Les ulis, 1996, 95. Hemostasis Manual, Sampol D, Arnoux B, Boutière. Released in January 1996.

[3] Samama, C.M., Barré, J. and Potron, G. (1992) Analysis of Hemostasis Preoperatively, the Hemostasis Assessment Must Be Prescribed in a Reasoned Manner According to the Questioning and Clinical Examination. Practitioner Review, 6, 38-44. 
[4] Sima-Zue, A., Benamar, B., Ngaka, D. and Nguemby, C. (1983) Evaluation of the Systematic Prescription of the Preoperative Assessment in an African Environment. Review. Anesthesia Notebooks, 46, 7-9.

[5] Sorol, L., Kouame, K.E., Kouame, S., N’chomotto, M.P., Anzou, I. and Amonkou, A. (2010) Systematic Preoperative Assessment: Interest in Orthopedic Surgery at Yopogon University Hospital. African Journal of Anesthesia and Emergency Medicine, 15, 76-98.

[6] Beye, M.D., Traoré, I., Leye, P.A., Traoré, M.M., Ndiaye, P.I., Feissal, A., et al. (2010) Enquête de satisfaction des patients sur la prise en charge anesthésique au CHU Aristide le Dantec de Dakar. African Journal of Anesthesia and Emergency Medicine, 15, 97-132.

[7] Koumare, A.K., Diop, A., Dolo, S., Ongoiba, N., Diallo, A. and Leroy, P. (1992) Proposition pour un bilan préopératoire sélectif. Medicine from Black Africa, 38 , 160-165.

[8] Blery, C. and Charpak, Y. (1990) Bilan préopératoire. In: Sam II, K., Ed., Anesthésie Réanimation chirurgicale, Médecine-Science, Flammarion, Paris.

[9] Haberer, J.P., Samama, C.M., Spahn, D. and Albreche, E. (2008) Hématologie et anesthésie Manuel pratique d'anesthésie. In: Practical Manual of Anesthesia, Elsevier Masson, Paris, 598.

[10] Dominique, L. (2001) Le Temps de Saignement doit-il être mesuré en préopératoire? Blood Venous Thrombosis, 13, 342-347.

[11] Groupe d'Etude sur l'Hémostase et la Thrombose (GEHT) (1985) Recommandations pour l'Evaluation préopératoire de l'hémostase. Blood Venous Thrombosis, 5, 5-14.

[12] Molliex, S., Pierre, S., Bléry, C., Marret, E. and Beloeil, H. (2012) Examens préinterventionnels systématiques-Routine preinterventional tests. French Annals of Anesthesia and Resuscitation, 31, 752-763.

https://sfar.org/wp-content/uploads/2015/10/AFAR Examens-preinterventionnelssystematiques.pdf

[13] Bonhomme, F., Ajzenberg, N., Schved, J.F., et al. (2013) Pre-Interventional Haemostatic Assessment: Guidelines from the French Society of Anaesthesia and Intensive Care. European Journal of Anaesthesiology, 30, 142-162. https://doi.org/10.1097/EJA.0b013e32835f66cd

[14] Tetchi, Y.D., Boua, N., Nguessan, Y.F., Binlin Dadie, R. and Mignonsin, D. (2006) La place des examens paracliniques préopératoires systématique. Expérience du Service d'Anesthésie Réanimation du CHU Treichville. International Journal of Medical Sciences, 8, 40-44.

[15] Lienhart, A., Teiboul, F., Broustet, J.P., Cohen-Bacrie, P., Dauizeau, L. and Flamant, Y., et al. (1998) Agence National d'Accréditation et d'Evaluation en Santé (ANAES) Service des recommandations et référence professionnelles. Les examens préopératoires systématiques, Paris, Anaes.

[16] Tomta, K., Mouzou, T., Egbohou, P., Bissang, A., Hemou, P. and Chobli, M. (2010) Cout de l'anesthésie dans un pays en Afrique Noire Francophone: Expérience du CHU Tokoin de Lomé. African Journal of Anesthesia and Emergency Medicine, 15, 51.

[17] Haberer, J.P. (1997) Examens complémentaires préopératoires. Médecine Thérapeutique, 3, 299-305.

[18] David, E., Nathan, N., Sol, I., Vincelot, A., Collet, D. and Granchamp, P. (2007) Un Bilan biologique est-il nécessaire pour réaliser une ALR obstétricale chez une pa- 
tiente dont l'interrogatoire et l'examen clinique sont strictement normaux? Annales Françaises d' Anesthésie et de Réanimation, 26, 705-710.

https://doi.org/10.1016/j.annfar.2007.05.007

[19] Practice Advisory for Preanesthesia Evaluation: An Updated Report by the American Society of Anesthesiologists Task Force on Preanesthesia Evaluation. Anesthesiology, 116, 522-538. https://doi.org/10.1097/ALN.0b013e31823c1067

[20] National Institute for Health Care Excellence (NICE) (2003) CG3 Preoperative Tests. https://www.nice.org.uk/Guidance/CG3

[21] Nathan, N. and Steib, A. (2007) Quelle anesthésie locorégionale est possible sous agents antiplaquettaires? University Teaching Days, Anesthesia and Resuscitation, Paris: Pitié-Salpêtrière, 135-141.

[22] Blery, C., Charpak, Y. and Nicoulet, I. (1994) Pratiques et attitudes actuelles des médecins anesthésistes en matière de prescription d'examens paracliniques préopératoires. Annales Françaises d Anesthésie et de Réanimation, 11, 576-583. https://doi.org/10.1016/S0750-7658(05)80763-4

[23] Lind, S.E. (1991) The Bleeding Time Does Not Predict Surgical Bleeding. Blood, 77, 2547-2552. https://doi.org/10.1182/blood.V77.12.2547.2547 